\title{
Perfil inflamatório e de degradação cartilagínea no líquido sinovial de cavalos Quarto de Milha de corrida com fraturas de carpo - resultados preliminares
}

Joice Fülber, Juliana Junqueira Moreira, Sarah Raphaela Torquato Seidel, Fernanda Rodrigues Agreste, Cynthia do Prado Vendrusculo, Luis Cláudio Lopes Correia da Silva, Raquel Yvonne Arantes Baccarin

*Autor correspondente

e-mail: baccarin@usp.br

\section{Resumo}

Cavalos atletas estão sujeitos a inúmeras lesões de origem musculoesquelética. A ocorrência de fraturas de carpo em cavalos Quarto de Milha de corrida pode estar relacionada com treinamento intenso em potros jovens, bem como estresse mecânico direto sobre os ossos do carpo, em decorrência da hiperextensão. A somatória destes fatores pode contribuir para a degradação cartilagínea, diminuindo a porcentagem de animais que retornam às atividades esportivas, bem como levando à aposentadoria precoce dos mesmos. O objetivo deste estudo foi determinar o perfil inflamatório e de degradação cartilagínea de cavalos Quarto de Milha que apresentaram fratura de carpo durante treinamento ou corrida, por meio de biomarcadores articulares no líquido sinovial (LS). Foram avaliados 12 cavalos com fratura de carpo, apresentando uma ou mais articulações cárpicas acometidas. Previamente à artroscopia foi coletado LS para contagem celular, teste de mucina, coloração, aspecto, viscosidade, determinação das concentrações de prostaglandina E2 (PGE2) por ELISA, condroitim sulfato (CS) e ácido hialurônico (AH) por eletroforese em gel de agarose 0,5\% e determinação do peso molecular do AH por eletroforese em gel de agarose 1\%. Após a cirurgia, todos os animais receberam fenilbutazona intravenoso, AH intra-articular e reabilitação por exercícios controlados semanais: repouso de 15 dias após a cirurgia e retorno gradual ao exercício com caminhadas guiadas no cabresto duas vezes ao dia, durante um a dois meses, passando para caminhadas guiadas pelo cabresto, seguido por trote, duas vezes ao dia, durante um a dois meses, em períodos de tempo variáveis conforme o caso, associado a flexões passivas das articulações. 0 retorno às atividades atléticas foi permitido após quatro meses em média. Os animais apresentaram idade media de três anos. Cinco animais (41,66\%) apresentaram apenas uma articulação cárpica acometida, cinco animais $(41,66 \%)$ apresentaram mais de uma articulação cárpica acometida no mesmo membro e dois animais apresentaram alterações bilaterais (16,66\%), totalizando 22 articulações. O LS apresentou coloração entre palha e ouro, aspecto límpido, teste 
de mucina classificado como bom na maioria dos animais, viscosidade entre 2 a 5 (50\%) e acima de 5 (50\%) e contagem média de células nucleadas de 159 células/uL. A concentração média de PGE2 foi 122,89 \pm $118,21 \mathrm{pg} / \mathrm{mL}$, de CS 39,66 $\pm 27,73 \mu \mathrm{g} / \mathrm{mL}$ e de AH 358,58 $\pm 120,44 \mu \mathrm{g} / \mathrm{mL}$. 0 percentual de AH de alto peso molecular foi de $73 \%$, sendo $29 \% 1000$ a $2000 \mathrm{kDa}, 29 \% 3000$ a $5000 \mathrm{kDa}, 33 \% 5000$ a $10000 \mathrm{kDa}$ e 9\% $>10000$ kDa. Altas concentrações de PGE2 no LS são relatadas em doenças inflamatórias e degenerativas. Os glicosaminoglicanos estudados (CS e AH) estão relacionados à homeostase articular, ou seja, a eventos biológicos relativos ao metabolismo da matriz extracelular, indicando ou não degradação da matriz cartilagínea. Nossos resultados sugerem processo inflamatório presente (aumento de PGE2), contudo não detectamos indícios de degradação da cartilagem (concentrações normais de CS e AH), apesar da presença de fragmentos intra-articulares. Podemos inferir que o tratamento artroscópico foi realizado dentro de um tempo adequado após o diagnóstico das fraturas em relação ao início da destruição cartilagínea. Estes resultados serão interpretados em próxima etapa, quando a relação entre o intervalo de tempo decorrido do diagnóstico da fratura à realização do tratamento e o exame físico no momento da colheita de líquido sinovial será avaliada. 0 retorno destes animais à atividade e sua performance atlética também serão comparados antes e após o tratamento. Tendo em vista os eventos que podem degradar a cartilagem articular, concluise que a retirada de fragmentos articulares decorrentes de fratura pode ser realizada antes dos mesmos iniciarem processo de degradação cartilagínea. Acredita-se que este procedimento implicará de forma direta no retorno destes animais às atividades de corrida.

Palavras-chave: Equinos. Fratura de carpo. Líquido sinovial. 